\title{
Corticosteroid-Induced Multifocal and Extensive Lipomatosis: A Case Report
}

\author{
Ilham Bouaddi ${ }^{1}$, Hanan Rkain ${ }^{1}$, Fadoua Allali ${ }^{1}$, Nazik Allali ${ }^{2}$, Najia Hajjaj-Hassouni ${ }^{1}$ \\ ${ }^{1}$ Department of Rheumatology B, El Ayachi Hospital, Rabat-Salé, Morocco; ${ }^{2}$ Department of Radiology, Avicenne Hospital, Rabat-Salé, \\ Morocco. \\ Email: drbouaddilham@yahoo.fr
}

Received September $10^{\text {th }}, 2011$; revised October $12^{\text {th }}, 2011$; accepted October $23^{\text {rd }}, 2011$.

\begin{abstract}
Introduction: Corticosteroid-induced lipomatosis are uncommon situation. We report a case of an extensive lipomatosis in a rheumatoid arthritis patient, who received a long term steroid therapy. Case report: A 49-year-old rheumatoid arthritis woman, who received for two years a mean dose of $15 \mathrm{mg} /$ day of prednisone equivalent, was admitted to the hospital for a six months history of progressive abdominal distension and dyspnea. Physical exam revealed typical symptoms of Cushing's syndrome and an important increase of abdominal volume. Lipomatosis diagnosis with mesenteric, mediastinal, retroperitoneal and epidural localizations, was rapidly confirmed by sonography and computed tomography (CT) exams. Management was based on corticosteroid reduction as well as use of hygiene and dietary measures. Therapeutic efficacy was noted on a clinical basis within one year. Discussion: lipomatosis occurs as a less known complication of long-term steroid therapy. Its localizations are numerous. Epidural and mediastinal lipomatosis are more frequent than mesenteric or retroperitoneal ones. Most frequently asymptomatic, lipomatosis could sometimes be revealed by false symptoms. Medical treatment including corticosteroid with drawal or reduction and calorie restriction, can lead to clinical improvement. Surgery is reseved in advanced forms with serious complications.
\end{abstract}

Keywords: Lipomatosis, Mesenteric, Retroperitoneal, Mediastinal, Epidural, Corticosteroids

\section{Introduction}

In rheumatoid arthritis (RA), oral corticosteroids are effective for the short term relief of symptoms. Their toxicity requires that they are used only when necessary, at the lowest dose possible and for the shortest duration of time. Long-term use of corticosteroids can lead to several complications. The Cushing's syndrome is the best model illustrating the adverse effects of corticosteroids. The lipomatosis steroid-induced is less known and was recently described [1]. We report a case of extensive lipomatosis in a rheumatoid arthritis patient and discuss characteristics of this pathology.

\section{Case Report}

A 49-year-old rheumatoid arthritis woman, who received for two years a mean dose of $15 \mathrm{mg} /$ day of prednisone equivalent, was admitted to the hospital for a six months history of progressive abdominal distension and dyspnea. Physical exam revealed and overweight (Body mass index at 29), typical symptoms of Cushing's syndrome and an important increase of abdominal volume (Figure 1).

Biological exams showed no abnormalities. An ab- dominopelvic and thoracic computed tomography (CT) scan showed collections of fat with an attenuation of -125 to -100 Hounsfield units. This deposition of adipose tissue was in mesenteric, mediastinal, retroperitoneal and epidural sites (Figures 2 and 3). Extensive and multifocal lipomatosis diagnosis was retained. Since patient was not under Disease-modifying antirheumatic drugs (DMAR- Ds), RA treatment was adjusted permitting to reduce progressively the daily dose of corticosteroids. Hygiene and dietary measures were also given to patient who was overweight. Within one year, therapeutic efficacy was noted on a clinical basis with $10 \mathrm{~cm}$ decrease of the umbilical perimeter.

\section{Discussion}

Lipomatosis represents a diffuse overgrowth of mature adipose tissue. It can be associated with obesity, steroid ingestion, or Cushing's syndrome or may be idiopathic [1].

Lipomatosis usually occurs for glucocorticoids dosages above $0.5 \mathrm{mg} / \mathrm{kg} / \mathrm{day}$ of prednisone equivalent [1-3]. The duration of treatment and cumulative dose seem to be the 


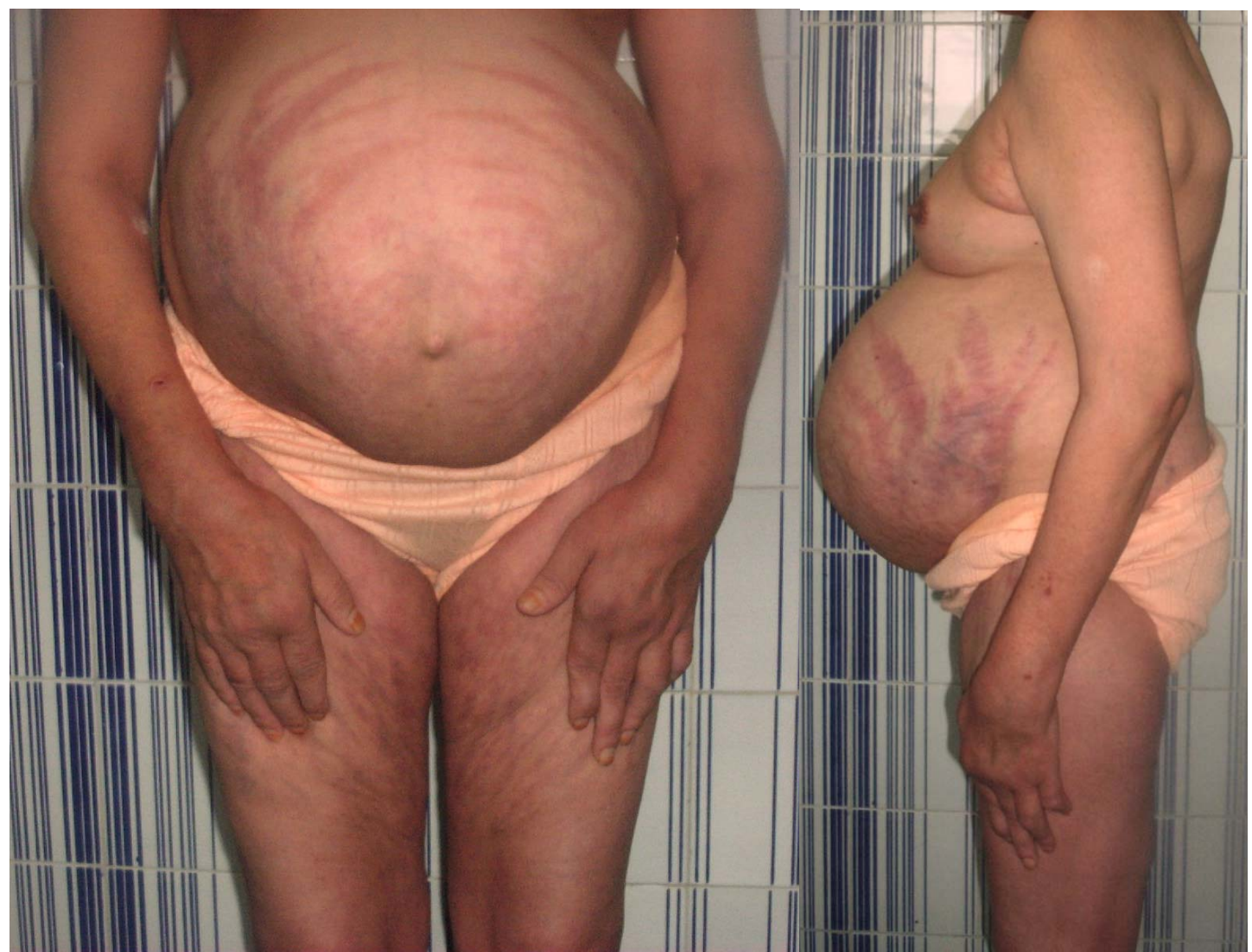

Figure 1: Photographs of the patient showing clinical signs of Cushing syndrome and the increase of abdominal volume.



Figure 2. Abdominal CT scan showing mesenteric and retroperitoneal lipomatosis.

more important determinants [3]. Our patient wasn't followed by a rheumatologist and therefore wasn't under DMARDS. The lack of adequate treatment of RA leads her to chronic use of corticosteroid at high dose.

Even if is not completely elucidated, glucocorticoid-

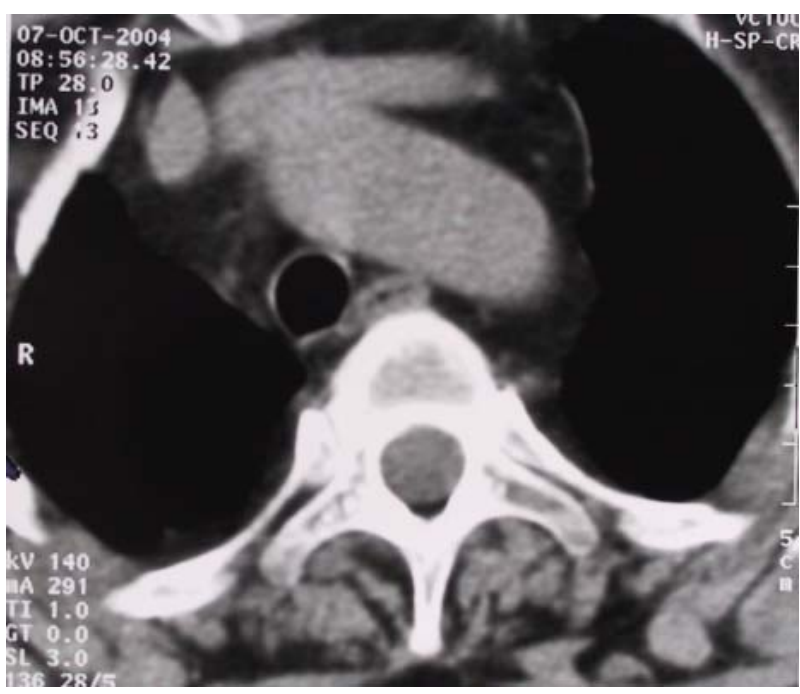

Figure 3. Chest CT scan showing mediastinal lipomatosis.

induced lipomatosis could be explained by the development of fatty deposits in brown adipose tissue by the reduction (secondary to steroid therapy) of the lipolytic activity dependent receptor beta-3-adrenergic [1].

The localizations of lipomatosis are numerous. Epidural and mediastinal lipomatosis are more frequent than 
mesenteric or retroperitoneal ones. Lipomatosis is usually asymptomatic nevertheless; many nonspecific symptoms could reveal this pathology [4,8-10]. In our patient persistent dyspnea was the principal symptom.

Diagnosis of "Corticosteroid-induced multifocal and extensive lipomatosis" in our case was retained by Computerized tomography. This imaging and magnetic resonance imaging are the principals tools to identify the differents localizations of lipomatosis [1,5].

Treatment of lipomatosis is essentially medical. It is based on the reduction or discontinuation of corticosteroid therapy if possible and the prescription of a hypocaloric diet, with restriction for four weeks of fast-acting carbohydrate [6,7]. This treatment helps to reduce the hyperinsulinemia and promotes lipolysis in adipose tissue [6,7]. A more rational approach and concerted effort should be applied in situations of corticosteroids use to minimize their adverse effects and to evict a lipomatosis complication. Our patient had a good evolution after diet and progressive reducing of glucocorticoids thanks to DMARDS onset. Surgery is required for complicated or rapidly evolving forms [1]. The risks of surgery are important in these patients; it should be discussed taking into account the clinical symptoms, the location and extent [2].

\section{Conclusions}

The lipomatosis steroid-induced is probably an underestimated entity because of the prevalence of asymptomatic forms. This diagnosis should be discussed in the context of long-term corticosteroid. The scanner and MRI are the key diagnostic tests, especially in the early stages. Medical treatment is the first line treatment. Surgery is reserved for complicated shapes.

\section{REFERENCES}

[1] S. Humblot, J. C. Weber, A. S. Korganow, B. Hammann,
J. L. Pasquali and T. Martin, "Les Lipomatoses Induites par la Corticothérapie,” La Revue de Médecine Interne, Vol. 18, No. 5, 1997, pp. 396-401.

[2] L. Dujardin, C. Marcelli, C. Hérisson and L. Simon, "La Lipo-Matose Epidurale: Une Complication de la Corticothérapie au Long Court, Apropos de Deux Cas,” La Revue de Médecine Interne, Vol. 17, No. 7, 1996, pp. 563-567.

[3] G. R. Fogel, “Cunningham PY 3rd, Esses SI. Spinal Epidural Lipomatosis: Case Reports, Literature Review and Metaanalysis,” Spine Journal, Vol. 5, No. 2, 2005, pp. 202-211.

[4] K. Q. Nguyen, C. Hoeffel, L. H. Le and H. T. Phan, "Mediastinal Lipomatosis,” South Medecine Journal, Vol. 91, 1998, pp. 1169-1172.

[5] J. Hierholzer, G. Bendorf, T. Lehmann, G. H. Schneider, P. Podrabski, B. Sander, et al., "Epidural Lipomatosis: Case Report and Literature Review," Neuroradiology, Vol. 38, No. 4, 1996, pp. 343-348.

[6] F. Laroche, P. Chemouilli, R. Carlier, D. Doyon and G. "Saïd Efficacité du Traitement Médical dans une Compression Médullaire par Lipomatose Epidurale Compliquant une Corticothérapie Prolongée,” Rev Rhum Ed Fr, Vol. 60, No. 11, 1993, pp. 846-849.

[7] W. E. George Jr, M. Wilmot, A. Greenhouse and M. Hammeke, "Medical Management of Steroid-Induced Epidural Lipomatosis," The New England Journal of Medicine, Vol. 308, No. 6, 1983, pp. 316-319. doi:10.1056/NEJM198302103080605

[8] V. Gilsanz, P. W. Brill, B. S. Wolf, "Increased Retroperitoneal Fat: A Sign of Corticosteroid Therapy,” Radiology, Vol. 123, 1977, pp. 147-148.

[9] M. Domínguez Domínguez, J. E. Camacho Gonzalez, A. Palacios Martinez, J. M. Gonzalez Montano, R. Quintero Rodriguez and R. Ibanez Suarez, "Pelvic Lipomatosis: Cause of Bladder Rupture,” Actas Urologicsa Espanolas, Vol. 25, No. 8, 2001, pp. 592-595.

[10] A. H. Zargar, B. A. Laway, S. R. Masoodi, M. H. Bhat, M. I. Bashir, A. I. Wani and N. A. Wani, "Diffuse Abdominal Lipomatosis," The Journal of The Association of Physicians India, Vol. 51, 2003, pp. 621-622. 